\title{
Evaluating the Effectiveness of Japanese Business Manner Education Using Council System Group Evaluation of the "Fundamental Competencies for Working Persons"
}

\author{
Yumi Fujihara \\ School of Management, Sanno University, Japan;
}

\begin{abstract}
In Japan, career education is obligatory for all students at universities and other institutions of higher education, and attention is currently being directed at the Fundamental Competencies for Working Persons, which are the basic abilities required to work together with various people in the workplace and in local communities as advocated by the Japanese Ministry of Economy, Trade and Industry (METI). At the same time, undergraduate education is being reconsidered from the standpoint of ensuring quality, and there have been more requests to conduct and measure the effects of educational programs on general-purpose, basic abilities in the modern workplace. Accordingly, this research focused on Japanese business manner education, which comprises manner education on the knowledge and skills related to a given occupation, as one facet of career education. It proposed a new Council System (CS) Group Evaluation method, based on the Japanese council system, which is a general decision-making method in Japanese business, for role-playing group work on Japanese business manners. In this study, this method was implemented for the multilateral verification of effects from the viewpoint of the Fundamental Competencies for Working Persons. As a result, we statistically confirmed the effects of peer evaluation and CS Group Evaluation on the Fundamental Competencies for Working Persons in business manner education, based on the results of questionnaire surveys administered to 210 students over a two-year period. Finally, it specified such future issues as the necessity for expanded, continual research on the generalizability of these results, as well as elucidating what elements of CS Group Evaluation effect the improvement of the Fundamental Competencies for Working Persons.
\end{abstract}

Keywords: Business manner education, Effect measurement, Fundamental Competencies for Working Persons, Peer evaluation, Council System Group Evaluation

\section{INTRODUCTION}

In Japan, career education has been obligatory in universities and community colleges (institutions of higher education) since FY2011 and, in recent years, career education has been drawing renewed attention. This is largely based on the Japanese Central Council for Education's (2011) [1] finding that young people today are not transitioning smoothly from school to society and the workplace. The Council has pointed out that the causes and background to this include structural issues throughout society as a whole. Their finding is based on a variety of data, including the approximately $7 \%$ unemployment rate for those aged 15 to 24, an approximately 30\% irregular employment rate, approximately 600,000 unemployed young people, and a turnover rate of $40 \%$ within three years for new university graduates, etc. The Council has also stated that "career education, which is education to facilitate career development by cultivating the abilities and attitudes that are the required foundation for the social and professional independence of each person" should be improved and enhanced in school education to meet social needs. It points out that basic, generalpurpose abilities will be especially required in the future and that the Fundamental Competencies for Working Persons, as advocated by the Japanese Ministry of Economy, Trade 
and Industry (METI), are one indicator of these basic, general-purpose abilities in career education.

Japan has entered an era in which the number of university places outnumbers the number of applicants, leading to the democratization of universities. However, attention is now being directed at ensuring educational quality at universities and other institutions of higher education. There is increasing demand from the public to reconsider undergraduate (bachelor's degree curriculum) education, with a call for educational programs that foster general-purpose, basic abilities; effective measurement of these abilities; and educational evaluation. For instance, the Japanese Cabinet Office's Council for the Implementation of Education Rebuilding (2007) [2] recommended "encouraging the building of structures in undergraduate education to measure the level of achievement for general-purpose, basic abilities."

Accordingly, this research focuses on Japanese business manner education as one facet of career education. It also proposes a new Council System (CS) Group Evaluation method, based on the Japanese council system, which is a general decision-making method used in Japanese business, for group work using role-playing. The main contents of such career education are an introduction to college life, understanding of business society, career design, and employment test measures. Basic scholastic ability (language, mathematics) may also be included. According to these classifications, the business manner education discussed in this study includes business social understanding, employment test measures, and basic scholastic ability (language). As such, we define business manner education as "manner education on the knowledge and skills related to a given occupation." In this study, this method was implemented for the multilateral verification of effects from the viewpoint of the Fundamental Competencies for Working Persons.

\section{Fundamental Competencies for Working Persons}

BACKGROUND AND LITERATURE REVIEW

Since 2006, the Japanese Ministry of Economy, Trade and Industry (METI) has advocated the Fundamental Competencies for Working Persons, which are the "basic abilities required in working together with various people in the workplace and in the local communities." As shown in Figure 1, these are composed of three competencies: the ability to step forward, the ability to think something through, and the ability to work in a team. These three competencies are composed of 12 competency factors. Specifically, the ability to step forward (action) is the "ability to step forward and act persistently even if you fail." It includes initiative, the ability to influence, and execution skill. The ability to think through (thinking) is the "ability to question and think through." It includes the ability to detect issues, planning skill, and creativity. The ability to work in a team (teamwork) is the "ability to collaborate with various people to achieve goals." It includes the ability to deliver messages, the ability to listen closely and carefully, flexibility, the ability to grasp situations, the ability to apply rules and regulations, and the ability to control stress. These Fundamental Competencies for Working Persons are based on suggestions from corporate human affairs staff, who report that many university graduates do not necessarily possess the abilities required of working persons. This standard was thus formulated for universities and corporations hiring employees to objectively evaluate their university education and level of attainment. METI created and released the Progress Sheet, a grading sheet that shows at a single glance the levels attained by the student in each competency. It is expected that universities will enter students' levels of achievement, etc., based on this standard, and that this will be helpful in corporate hiring [3]. 
Figure 1. Fundamental Competencies for Working Persons.

\section{Fundamental Competencies for Working Persons}
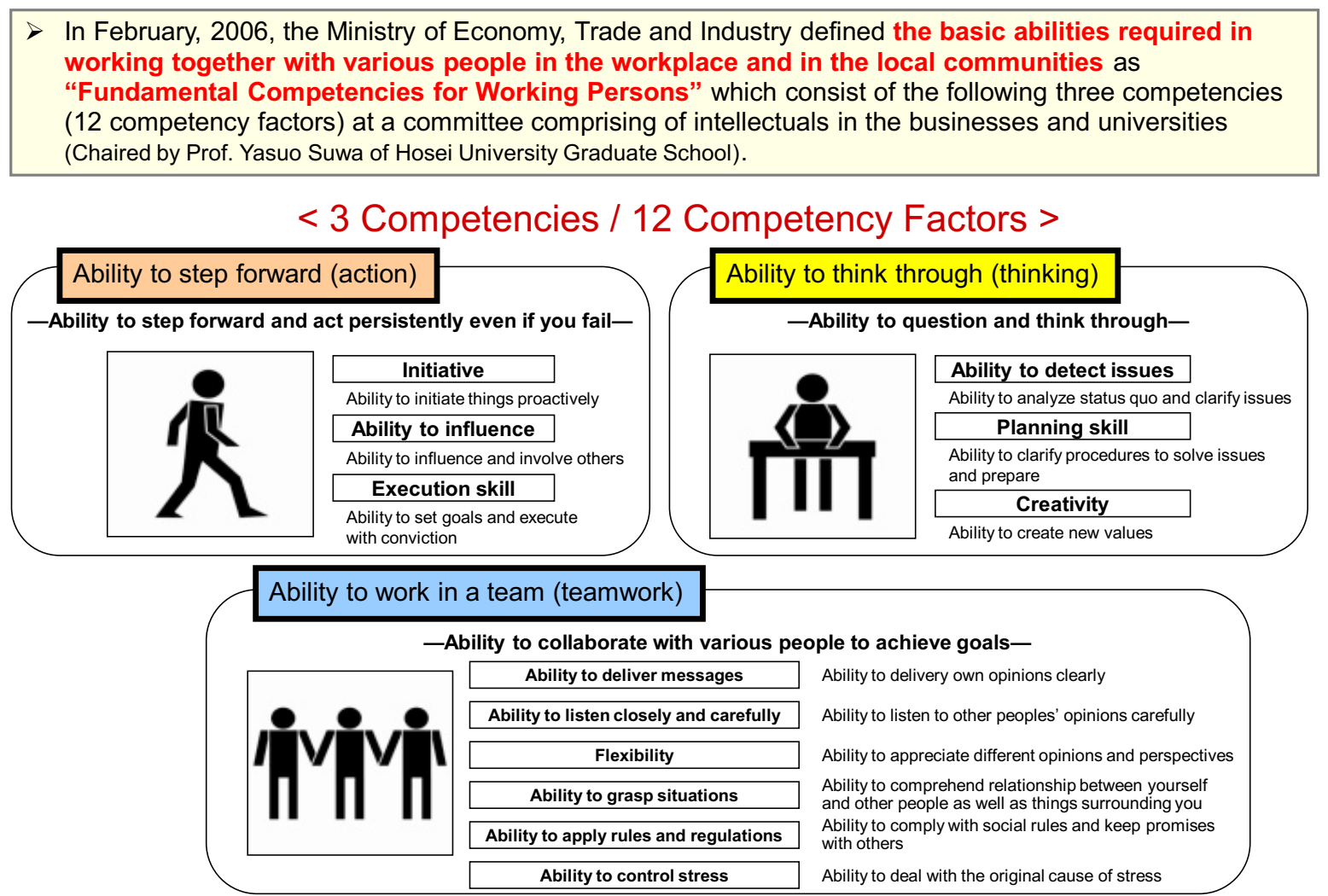

Source: METI (2006) [3]

In addition to the Fundamental Competencies for Working Persons, the generic skills advocated in Japan are defined in various ways, including the Ministry of Education, Culture, Sports, Science and Technology's Bachelor's Degree Skills; the Ministry of Health, Labour and Welfare's Employability; the Cabinet Office's Human Skills and Employment Skills; the Organization for Economic Cooperation and Development's (OECD) key competencies; and the Recruit Works Institute's Fundamental Competencies. A unique characteristic of the Fundamental Competencies for Working Persons is that they stress the importance of the skills required in the economic world. To that end, this research focuses on developing these competencies from the viewpoint of job-hunting support in career education.

\section{Past Research on Group Evaluation and the Position of this Research}

In 2015, the authors conducted research on peer evaluation [4] of role-playing in group work, in the context of business manner education, which is one facet of career education. However, the aforementioned research did not focus on the effectiveness of group evaluation. One effect of group evaluation is that it boosts the group's awareness. Ikari [5], for example, stresses the importance of group evaluation, stating that it is important to incorporate group work into career design courses and implement group evaluation rather than individual evaluation. This is because, in some cases, not all members participate actively in group work, so implementing group evaluation and making the group responsible for the class encourages the awareness that non-active participation will lead to lowered evaluations for other members. This enables members to cultivate the skill of persistently executing something with their fellow members according to the roles they are capable of fulfilling. Tanimoto [6] points out that, among the 12 Competency Factors in the Fundamental Competencies for Working Persons described above, the ability to work in a team (teamwork) plays a core role and consists of six competency 
factors (half of the total). Thus, it is expected that incorporating group evaluation will boost the group's awareness, thereby enhancing teamwork and also improving the Fundamental Competencies for Working Persons.

In general group work, etc., "group evaluation" means that the party being evaluated (evaluatee) is a group rather than an individual. In the Japanese Central Council for Education's 2012 report [7], attention is directed at group work as part of active learning, yet there has, to date, been little research on group evaluation. The Encyclopedia of Contemporary Education Evaluation [8] includes information about self-evaluation and peer evaluation, but nothing about group evaluation. Moreover, past research on group evaluation shares the common feature of having groups be the evaluatee, but the evaluators comprise different persons including teachers, other groups, and student members of the group (individuals). The Encyclopedia of Contemporary Education Evaluation [8] reads, "The characteristic of selfevaluation is that the evaluator and evaluatee are the same person." As far as the authors know, however, there are no reports in which the evaluators and evaluatees comprise the same group members.

Examining past research on group evaluation in terms of its evaluators, teachers performed the group evaluations in the career design course conducted in the previously mentioned Ikari [5]. Kagawa [9] reported on group evaluation in cooking lessons as part of a high school home economics course, but this evaluation was also performed by teachers. Adachi et al. [10] reported on peer evaluation and group evaluation in an information processing class for university students, but the group evaluation was performed by individual students. If one allows the similar terms "group evaluation" and "team evaluation" to refer to the same phenomenon, then Nishitani [11] implemented team evaluation in a computer algebra lesson for university students, but this evaluation was performed by teachers. Tamura et al. [12] reported on team evaluation from the standpoint of team medical care, but these evaluations were also conducted by individual students. In business situations, Misawa et al. [13] conducted continuous research on team evaluation for thermal power stations, but these were also performed by individuals rather than the teams themselves.

Accordingly, this research proposes a new education evaluation method for group evaluation in which the evaluators and evaluatees comprise members of the same group. To distinguish this group evaluation from general group evaluation, in this research it is called CS Group Evaluation, and is defined as, "Evaluating one's own group based on a council with all group members during group work." The term "Council (Gogi)" means "Discussions with two or more people" (Kojien, 2008) [14]. "Council system (Gogisei)" means, "A system in which councils are used for deliberation and decision" (Kojien, 2008) [14]. The council system is the most regularly used decision-making method in Japanese government and business. Considering this, it is thought that this method can contribute to developing the Fundamental Competencies for Working Persons in Japan, yet it has not been the focus of attention in past career education evaluation. METI [15] reported that having students reflect on their own actions based on selfevaluation results, encouraging them to observe their growth and the abilities they lack, and consciously working to improve the Fundamental Competencies for Working Persons is essential in evaluation methods for these competencies. The same results can be expected in group evaluation.

\section{Objectives}

The hypothesis of this research is that group awareness can be enhanced to increase the Fundamental Competencies for Working Persons by implementing CS Group Evaluation, in 
addition to peer evaluation in business manner education, which is conducted as one facet of career education. On this basis, the following procedures were performed.

First, the objective of this research was to design and operate a new education evaluation method and verify its effects. The characteristic of this method was to implement the CS Group Evaluation in group work to develop the Fundamental Competencies for Working Persons. The effects of peer evaluation in group work using role-playing, as clarified in Fujihara and Maeno [2015][4], will also be continually verified from the viewpoint of the Fundamental Competencies for Working Persons. As a future issue, we plan to conduct continual surveys on peer evaluation effects, as described in our previous study [4]. Furthermore, this research verifies whether or not group evaluations are higher than individual evaluations with respect to the Fundamental Competencies for Working Persons when CS Group Evaluation is implemented-in other words, we verify whether working as a group is more effective than individual work for developing these competencies.

The CS Group Evaluation that is the characteristic of this research can be described in a matrix plotting the evaluator on the vertical axis and the evaluated on the horizontal axis (Figure 2). Specifically, it expresses that CS Group Evaluation is an effective evaluation method that includes the characteristics of traditional self-evaluation, other-evaluation by other group members, and peer evaluation.

Figure 2. CS Group Evaluation matrix.

\begin{tabular}{|c|c|c|c|}
\hline Evaluator & Me & $\begin{array}{c}\text { You } \\
\text { (G roup M em ber, } 0 \text { ther G roup) }\end{array}$ & $\begin{array}{l}\text { Us } \\
\text { O ur G roup) }\end{array}$ \\
\hline I & Se ff-Evaluation & 0 ther-Evaluation & G roup Evaluation \\
\hline $\begin{array}{l}\text { You } \\
\text { (G roup M em ber, } 0 \text { ther } \\
\text { G roup, Teacher) }\end{array}$ & 0 ther-Evaluation & Se lf-Evaluation & G roup Evaluation \\
\hline $\begin{array}{c}\text { We } \\
(0 \text { ur } G \text { roup) }\end{array}$ & 0 ther-Evaluation & 0 ther-Evaluation & $\begin{array}{c}\text { Counc il System G roup } \\
\text { Evaluation }\end{array}$ \\
\hline
\end{tabular}

Modified from Fujihara and Maeno (2017) [17]

\section{Research Method Overview}

\section{METHOD}

This research was performed using the following procedures. First, a general view was obtained of business manner education utilizing peer evaluation via group work using roleplaying, as clarified in our previous research [4]. Next, research was conducted from the viewpoint of generally describing and designing an education evaluation method utilizing the CS Group Evaluation through group work, which was newly developed for this research.

Next, to measure the effects of peer evaluation and CS Group Evaluation in group work, questionnaire surveys evaluating the Fundamental Competencies for Working Persons were administered to a total of 215 students in four classes (two in each year) during a two-year period from FY2014 (Survey 1) to FY2015 (Survey 2). These classes were part of a business manner course ("this course") provided in the first semester for first-year students of a management course at a private university in Tokyo Prefecture. This research also confirmed whether the students were developing their competencies-regardless, for example, of the special characteristics of students in that fiscal year-by analyzing the data over the two years from FY2014 to FY2015 rather than a single fiscal year, and by increasing the number of students being surveyed. 
Based on the survey results, the following three survey analyses were performed. Analysis 1 compared the pre- and post-class survey results. Analysis 2 compared the classes with CS Group Evaluation and those without. Analysis 3 compared and analyzed the CS Group Evaluation and individual evaluation. Analysis 1 was performed to verify the peer evaluation effects in group work using role-playing from the viewpoint of the Fundamental Competencies for Working Persons, which is an objective of this paper. Analysis 2 was performed to verify the effects of the CS Group Evaluation in group work. Implementing the CS Group Evaluation, Analysis 3 was performed to verify if the effects of group evaluation were higher in the competencies than in the effects of individual evaluation in the post-class surveys.

Finally, to more deeply consider these analysis results, this paper gives some consideration to the Fundamental Competencies for Working Persons as implemented using the CS Group Evaluation in particular. It also organizes their effects and significance, and suggests future challenges.

\section{Survey Method}

\section{Survey 1}

A total of 105 students participated in Survey 1: 50 students in Class A who implemented the CS Group Evaluation, and 55 students in Class B who did not. The first author oversaw these two classes for students taking this course in FY2014. Regarding the timing of the surveys, the Fundamental Competencies for Working Persons self-evaluation questionnaire was administered in the pre-class survey during the first class (April) and post-class survey during the final class (July). The questionnaire sheet was produced based on METI's [15] Fundamental Competencies for Working Persons Level Evaluation Standard Chart. The survey items comprised the 12 Fundamental Competencies for Working Persons items shown in Figure 1. The survey rating scale comprised a five-point Likert scale ranking level and quality (five: strongly agree, four: agree, three: neutral, two: disagree, one: strongly disagree). A group evaluation section was added as well as a section for writing the evaluation basis (specific, actual actions) and a free-comment section. When performing the evaluations, an example was given of the METI [15] Level Evaluation Standard Chart so the students could carry out their evaluations properly.

When the questionnaire was distributed, it was explained that participation was voluntary, that respondents could leave blank those questions they did not wish to answer, that they could stop answering questions when they wished, that they did not have to fill in their names, and that the data would be treated mechanically with a duty of confidentiality. There is no conflict of interest in this study.

\section{Survey 2}

A total of 110 students participated in Survey 2: 55 students in Class A with CS Group Evaluation, and 55 students in Class B without. The first author oversaw these two classes for students taking this course in FY2015. The timing, survey items, rating scale, and study ethics were the same as for Survey 1.

\section{Survey analysis methods}

Based on the data from Surveys 1 and 2, to statistically judge the educational effects of this course, the mean values and standard deviations in Analysis 1 were calculated for each item for the pre-class survey, post-class survey, and growth values (subtracting the pre-class evaluation from the post-evaluation) for each item. These were compared using the Wilcoxon rank sum test (Tables 1,2). The Wilcoxon rank sum test was also conducted to compare the 
growth values for the classes with and without the CS Group Evaluation in Analysis 2 (Table 3), and to compare the mean values for post-class evaluations (group evaluation and individual evaluation) for the class that implemented the CS Group Evaluation in Analysis 3 (Table 4). The Wilcoxon rank sum test was chosen because this sample comprises dispersed data. There was concern that, when using a $t$-test presupposed on a normal distribution, the test results would overestimate the significance of the different mean values between the pre- and post-class evaluations.

\section{Business Manner Course Overview Peer evaluation characteristics}

Business manner evaluations frequently depend on objective evaluations by customers or other persons, rather than by oneself. Therefore, in our previous research [4], we proposed a method for peer evaluation in group work. This paper continues to confirm the effects of peer evaluation with the goal of developing the Fundamental Competencies for Working Persons. The class process and characteristics are shown in Figure 3.

The class was conducted using a role-play of business manners, comprising actions in which each person adopted a specific role (e.g., as a receptionist, secretary, visitor, or boss) and acted out being that character, in a group work scenario. Specifically, until Step 3, the process was the same as that used in Fujihara and Maeno (2015) [4]. At each application, the following process was repeated. The participants prepared in advance for an individual role-playing assignment, such as a visitor receptionist during the absence of the boss (Step 1). First, all group members role-played being a visitor receptionist (with words and actions) as individual presentations, while the other group members performed the roles of visitors. The members performed self-evaluations and also received other-evaluations from group members (Step 2). As the receptionist and visitors, the group presented their role-plays to the class, performed a self-evaluation of the group, and received other-evaluations from other groups as well as teachers (Step 3). According to the viewpoint of developing the Fundamental Competencies for Working Persons, work in actual society often involves cooperation with multiple persons rather than just individual work. This is why not only individuals but the whole group presented; consequently, not only individual evaluations but group evaluations were then performed. 
Figure 3. Class process and characteristics.

\begin{tabular}{|c|c|}
\hline $\begin{array}{c}\text { Step } 1 \\
\text { Individual Work } \\
(30 \mathrm{~min} .)\end{array}$ & $\begin{array}{l}\text {-Individual assignment in preparation } \\
\text { e.g., Role-playing about a visitor receptionist during } \\
\text { absence of boss (words and actions) }\end{array}$ \\
\hline $\begin{array}{l}\text { Stélass (90 min.) } \\
\text { Group Work } \\
\text { (45 min.) }\end{array}$ & $\begin{array}{l}\text { - Role-playing by individuals in each group } \\
\text { - Peer-Evaluation (positive and negative point ) } \\
\text { Self-Evaluation } \\
\text { Other-Evaluation from group member }\end{array}$ \\
\hline $\begin{array}{l}\text { Step } 3 \\
\text { Presentation } \\
(30 \text { min. })\end{array}$ & $\begin{array}{l}\text { - Role-playing by group in class } \\
\text { - Peer-Evaluation (positive and negative point) } \\
\text { Group Evaluation from other groups and teacher }\end{array}$ \\
\hline $\begin{array}{l}\text { Step } 4 \\
\text { Reflection } \\
\text { Evaluation } \\
\text { (15 min.) }\end{array}$ & $\begin{array}{l}\text { As a point of view "Fundamental Competencies for Working } \\
\text { Persons" } \\
\text {-Self-Evaluation } \\
\text { Just for class A with Council System Group Evaluation } \\
\text { - Council system Group Evaluation } \\
\text { Evaluating one's own group based on a council with all } \\
\text { group members during group work }\end{array}$ \\
\hline
\end{tabular}

Modified from Fujihara and Maeno (2017) [17]

\section{Characteristics of the CS Group Evaluation}

In this research, self-evaluations were repeated in each class from the viewpoint of the Fundamental Competencies for Working Persons and as one facet of reflection at the end of each class (Step 4). Specifically, in each class the students indicated the positive elements and those that should be improved with reference to the Fundamental Competencies for Working Persons, always adding the reasons (actual actions) for their feedback to ensure it would be useful in the future. In addition, the class with the CS Group Evaluation repeatedly performed these evaluations (councils evaluating their own group) in each class. The entire group reflected, held councils on, and wrote down the positive elements and those that should be improved regarding the overall group's Fundamental Competencies for Working Persons, as well as the reasons for their evaluation based on specific examples, just like the previously described self-evaluation (Step 4). In the final class, the students filled in the evaluation sheets, based on the previously described Fundamental Competencies for Working Persons Level Evaluation Standard Chart from METI [15]. In doing so, they wrote down their evaluations from the overall class and specific, actual actions that should be taken. METI [15] states that self-evaluation and reflection should be performed as often as possible, as methods to evaluate the Fundamental Competencies for Working Persons. It notes that capacity building is important, and that it is essential to confirm actual actions that have improved in relation to the built capacity. It is also essential to set improvement goals based on actual actions due to lowering abilities. This research referred to this information.

It has been noted that problem-solving using Problem-based Learning (PBL) is an effective educational method for developing the Fundamental Competencies for Working Persons [16]. However, in implementing PBL, while the entire university must systematically introduce it to some degree, not all teachers can immediately introduce this method. Due to an upper limit to the number of students that can participate in PBL, not all students can participate immediately. To that end, the authors focused on the utilization of group work as a measure for which a certain level of effects can be expected, and one that can be introduced to existing class 
courses with comparative ease. The business manner course discussed in this research was conducted via group work using role-playing. The groups worked together to tackle a single exercise assignment in each class. The authors believed this could be interpreted as a type of repetitive, small-scale PBL in the broad sense of the word.

\section{Survey 1 (FY2014)}

\section{RESULTS}

The results of the pre-class evaluation (first class) and post-class evaluation (final class) were analyzed to see if the participating students had improved their Fundamental Competencies for Working Persons. The FY2014 survey is shown in Figure 1. First, examining the growth values (post-class evaluation minus pre-class evaluation), the mean growth value was 0.62 points for the class with the CS Group Evaluation. The items in order of highest growth value were (7) ability to deliver messages 0.84 , (8) ability to listen closely and carefully 0.76 , and (3) execution skill 0.74 . The items in order of lowest growth value were (9) flexibility 0.40 and (10) ability to grasp situations 0.46 . The mean growth value for the class without CS Group Evaluation was 0.33 points. The items in order of highest growth value were (7) ability to deliver messages $0.50,(2)$ ability to influence 0.45 , and (8) ability to listen closely and carefully 0.40 . The items in order of lowest growth value were (9) flexibility 0.24 and (10) ability to grasp situations 0.27 .

Next, statistically judging the educational effects of this course, mean and standard deviation values were found for the pre- and post-class evaluations. Using the Wilcoxon signed-rank test to compare, among the 12 Competency Factors, the mean values for (9) flexibility and (10) ability to grasp situations improved for the class with the CS Group Evaluation although no significant differences were recognized. However, all three competencies were improved significantly overall. For the class without the CS Group Evaluation, the mean values for (6) creativity, (9) flexibility, and (11) ability to apply rules and regulations increased, although no significant differences were recognized. On the other hand, all three competencies were improved significantly overall.

Table 1. Comparison between pre- and post-class evaluations (FY2014).

\begin{tabular}{|c|c|c|c|c|c|c|c|c|c|c|c|c|}
\hline \multirow[b]{2}{*}{$\begin{array}{c}\text { Fundam ental C om petenc ies } \\
\text { for W orking Persons } \\
\text { FY2014) }\end{array}$} & \multicolumn{6}{|c|}{$\begin{array}{l}\quad \text { C lass } \mathrm{A} \quad \mathrm{N}=50) \\
\text { w ith Counc il System G roup Evaluation }\end{array}$} & \multicolumn{6}{|c|}{$\begin{array}{l}\text { C lass B } \mathbb{N}=55) \\
\text { w ithout C ounc il System G roup Evaluation }\end{array}$} \\
\hline & \begin{tabular}{|c|} 
Pre-c lass \\
evaluation \\
average
\end{tabular} & \begin{tabular}{|c|} 
Post-c lass \\
evaluation \\
average \\
\end{tabular} & $\begin{array}{l}\text { G row th- } \\
\text { value } \\
\text { Post-Pre) }\end{array}$ & \multicolumn{2}{|c|}{ P-value } & $\begin{array}{l}\text { Post-class } \\
\text { group } \\
\text { evaluation } \\
\text { average }\end{array}$ & \begin{tabular}{|c|} 
Pre-class \\
evaluation \\
average
\end{tabular} & \begin{tabular}{|c|} 
Post $-c$ lass \\
evaluation \\
average
\end{tabular} & \begin{tabular}{|c|} 
G row th- \\
value \\
Post-Pre)
\end{tabular} & \multicolumn{2}{|c|}{$P$-value } & $\begin{array}{l}\text { Post-class } \\
\text { group } \\
\text { evaluation } \\
\text { average }\end{array}$ \\
\hline \multicolumn{13}{|l|}{ Action } \\
\hline (1) In itiative & 2.86 & 3.38 & 0.52 & 0.003 & $* * *$ & 3.72 & 3.25 & 3.60 & 0.35 & 0.044 & $* *$ & 3.75 \\
\hline (2) Ability to influence & 2.62 & 3.22 & 0.60 & 0.025 & ** & 3.66 & 3.13 & 3.58 & 0.45 & 0.020 & ** & 3.44 \\
\hline (3) Execution skill & 2.66 & 3.40 & 0.74 & 0.014 & ** & 4.20 & 3.29 & 3.62 & 0.33 & 0.008 & $* * *$ & 3.69 \\
\hline Subtota & 8.14 & 10.00 & 1.86 & 0.002 & $* * *$ & 11.58 & 9.67 & 10.80 & 1.13 & 0.002 & $* * *$ & 10.87 \\
\hline \multicolumn{13}{|l|}{ Thinking } \\
\hline (4) Ability to detect issues & 2.62 & 3.20 & 0.58 & 0.001 & *** & 3.50 & 2.96 & 3.24 & 0.28 & 0.073 & * & 3.16 \\
\hline (5) P lanning skill & 2.30 & 3.00 & 0.70 & 0.002 & $* * *$ & 3.36 & 2.64 & 3.00 & 0.36 & 0.015 & ** & 3.36 \\
\hline (6) Creativity & 2.36 & 3.08 & 0.72 & 0.002 & $* * *$ & 3.58 & 3.02 & 3.22 & 0.20 & 0.363 & & 3.15 \\
\hline Subtota & 7.28 & 9.28 & 2.00 & 0.000 & $* * *$ & 10.44 & 8.62 & 9.45 & 0.83 & 0.026 & $*$ & 9.67 \\
\hline \multicolumn{13}{|l|}{ Team w ork } \\
\hline (7) Ability to de liver m esseges & 2.46 & 3.30 & 0.84 & 0.000 & $* * *$ & 3.54 & 2.95 & 3.45 & 0.50 & 0.004 & $* * *$ & 3.60 \\
\hline $\begin{array}{l}\text { (8) Ability to listen c bsely } \\
\text { and carefull }\end{array}$ & 3.10 & 3.86 & 0.76 & 0.000 & *** & 3.96 & 3.56 & 3.96 & 0.40 & 0.011 & $*$ & 3.64 \\
\hline (9) Flexbility & 3.06 & 3.46 & 0.40 & 0.118 & & 3.76 & 3.36 & 3.60 & 0.24 & 0.110 & & 3.85 \\
\hline (10) Ability to grasp situation & 2.98 & 3.44 & 0.46 & 0.106 & & 3.98 & 3.33 & 3.60 & 0.27 & 0.042 & $* *$ & 3.51 \\
\hline $\begin{array}{l}\text { (11) Ability to apply rules and } \\
\text { regulations }\end{array}$ & 2.94 & 3.50 & 0.56 & 0.072 & * & 3.66 & 3.36 & 3.64 & 0.28 & 0.115 & & 3.58 \\
\hline (12) Ability to contro I stress & 2.88 & 3.40 & 0.52 & 0.030 & $* *$ & 3.82 & 3.02 & 3.36 & 0.34 & 0.067 & $*$ & 3.40 \\
\hline Subtota & 17.42 & 20.96 & 3.54 & 0.001 & $* * *$ & 22.72 & 19.58 & 21.60 & 2.02 & 0.000 & $* * *$ & 21.58 \\
\hline \multirow{2}{*}{ Tota } & 32.84 & 40.24 & 7.40 & 0.000 & $* * *$ & 44.74 & 37.87 & 41.85 & 3.98 & 0.000 & $* * *$ & 42.13 \\
\hline & \multicolumn{2}{|c|}{ G rowth-value average } & 0.62 & \multicolumn{3}{|c|}{$* * *<0.01, * *<0.05, *<0.10$} & \multicolumn{2}{|c|}{ G rowth-value average } & 0.33 & \multicolumn{3}{|c|}{$* * *<0.01, * *<0.05, *<0.10$} \\
\hline
\end{tabular}




\section{Survey 2 (FY2015)}

Just like FY2014, the results of the pre-class evaluation (first class) and post-class evaluation (final class) were analyzed to ascertain if the students taking this course had improved their Fundamental Competencies for Working Persons. The FY2015 survey is shown in Figure 2. First, looking at the growth values, the mean growth value was 0.83 points for the class with the CS Group Evaluation. The items in order of highest growth value were (3) execution skill 1.16 , (8) ability to listen closely and carefully 1.07 , and (7) ability to deliver messages 1.00 . The items in order of lowest growth value were (9) flexibility 0.49 , (10) ability to grasp situations 0.60 , and (11) ability to apply rules and regulations 0.60 . The mean growth value for the class without the CS Group Evaluation was 0.55 points. The items in order of highest growth value were (7) ability to deliver messages 0.90 and (8) ability to listen closely and carefully 0.84 . The items in order of lowest growth value were (11) ability to apply rules and regulations 0.28 and (4) ability to detect issues 0.39 .

Next, the Wilcoxon signed-rank test revealed that all three competencies and 12 competency factors improved significantly for the class with the CS Group Evaluation. For the class without it, among the 12 Competency Factors, the mean value for (11) the ability to apply rules and regulations increased although no significant difference was recognized. On the other hand, all three competencies were improved significantly overall.

Table 2. Comparison between pre- and post-class evaluations (FY2015).

\begin{tabular}{|c|c|c|c|c|c|c|c|c|c|c|c|c|}
\hline \multirow{2}{*}{$\begin{array}{c}\text { Fundam ental } \mathrm{C} \text { om petenc ies } \\
\text { for W orking Persons } \\
\text { (FY2015) }\end{array}$} & \multicolumn{6}{|c|}{$\begin{array}{l}\text { C lass } \mathrm{A} \quad \mathrm{N}=55) \\
\text { with Counc il System G roup Evaluation }\end{array}$} & \multicolumn{6}{|c|}{$\begin{array}{c}\text { C lass B } \mathbb{N}=55) \\
\text { w ithout C ounc il System G roup Evaluation }\end{array}$} \\
\hline & \begin{tabular}{|c|} 
Pre-c lass \\
evaluation \\
average
\end{tabular} & \begin{tabular}{|c|} 
Post-c lass \\
evaluation \\
average
\end{tabular} & $\begin{array}{l}\text { G row th- } \\
\text { value } \\
\text { Post-Pre) }\end{array}$ & \multicolumn{2}{|c|}{$P$-value } & $\begin{array}{c}\text { Post-c lass } \\
\text { group } \\
\text { eva luation } \\
\text { average }\end{array}$ & \begin{tabular}{|c|} 
Pre-c lass \\
evaluation \\
average
\end{tabular} & \begin{tabular}{|c|} 
Post $-c$ lass \\
evaluation \\
average
\end{tabular} & \begin{tabular}{|c|} 
G row th- \\
value \\
Post-Pre)
\end{tabular} & \multicolumn{2}{|c|}{$P$-value } & \begin{tabular}{|c|} 
Post-class \\
group \\
evaluation \\
average
\end{tabular} \\
\hline \multicolumn{13}{|l|}{ Action } \\
\hline (1) In itiative & 2.75 & 3.49 & 0.84 & 0.000 & ** & 3.76 & 2.85 & 3.47 & 0.62 & 0.000 & ** & 4.02 \\
\hline (2) Ability to infuence & 2.15 & 3.13 & 0.98 & 0.000 & **** & 3.67 & 2.60 & 3.20 & 0.60 & 0.001 & ** & 3.71 \\
\hline (3) Execution skill & 2.33 & 3.49 & 1.16 & 0.000 & **** & 3.33 & 2.85 & 3.51 & 0.66 & 0.000 & ** & 3.53 \\
\hline Subtota & 7.22 & 10.11 & 2.89 & 0.000 & *** & 10.76 & 8.31 & 10.18 & 1.87 & 0.000 & $* *$ & 11.25 \\
\hline \multicolumn{13}{|l|}{ Thinking } \\
\hline (4) Ability to detect issues & 2.40 & 3.24 & 0.84 & 0.000 & **** & 3.13 & 2.85 & 3.24 & 0.39 & 0.017 & ** & 3.55 \\
\hline (5) P lann ing skill & 2.42 & 3.16 & 0.74 & 0.000 & **** & 3.07 & 2.60 & 3.04 & 0.44 & 0.004 & $* *$ & 2.47 \\
\hline (6) C reativity & 2.20 & 2.82 & 0.62 & 0.000 & **** & 2.73 & 2.62 & 3.04 & 0.42 & 0.013 & ** & 3.78 \\
\hline Subtota & 7.02 & 9.22 & 2.20 & 0.000 & **** & 8.93 & 8.07 & 9.31 & 1.24 & 0.001 & ** & 9.80 \\
\hline \multicolumn{13}{|l|}{ Team work } \\
\hline (7) Ability to de liver m esseges & 2.27 & 3.27 & 1.00 & 0.000 & *** & 3.65 & 2.45 & 3.35 & 0.90 & 0.000 & $* *$ & 3.60 \\
\hline $\begin{array}{l}\text { (8) Ability to listen c bse ly } \\
\text { and carefull }\end{array}$ & 2.73 & 3.80 & 1.07 & 0.000 & *** & 4.13 & 2.98 & 3.82 & 0.84 & 0.000 & ** & 3.69 \\
\hline (9) Flexbility & 2.76 & 3.25 & 0.49 & 0.001 & **** & 3.38 & 2.93 & 3.36 & 0.43 & 0.003 & $* *$ & 3.40 \\
\hline (10) Ability to grasp situation & 2.64 & 3.24 & 0.60 & 0.000 & **** & 3.65 & 3.07 & 3.49 & 0.42 & 0.005 & $* *$ & 3.69 \\
\hline $\begin{array}{l}\text { (11) Ability to apply rules and } \\
\text { regulations }\end{array}$ & 2.75 & 3.35 & 0.60 & 0.000 & $* * *$ & 3.36 & 3.16 & 3.44 & 0.28 & 0.135 & & 3.78 \\
\hline (12) Ability to contro / stress & 2.42 & 3.38 & 0.96 & 0.000 & $* * *$ & 3.55 & 2.80 & 3.36 & 0.56 & 0.004 & $* *$ & 4.16 \\
\hline Subtota & 15.57 & 20.29 & 4.72 & 0.000 & **** & 21.72 & 14.60 & 20.82 & 3.43 & 0.000 & $* *$ & 22.33 \\
\hline Tota & 29.81 & 39.62 & 9.81 & 0.000 & **** & 41.41 & 30.98 & 40.31 & 6.54 & 0.000 & ** & 43.38 \\
\hline & \multicolumn{2}{|c|}{ G row th-value average } & 0.83 & \multicolumn{3}{|c|}{$* * *<0.01, * *<0.05, *<0.10$} & \multicolumn{2}{|c|}{ G row th-value average } & 0.55 & \multicolumn{3}{|c|}{$* * *<0.01, * *<0.05, *<0.10$} \\
\hline
\end{tabular}

Modified from Fujihara and Maeno (2017) [17]

\section{DISCUSSION}

\section{Comparison and Verification via Pre- and Post-Class Evaluations (Analysis 1)}

Examining the results of both Survey 1 (FY2014, Table 1) and Survey 2 (FY2015, Table 2), the authors could confirm significant increases in the growth values (post-class evaluation minus pre-class evaluation) for all three competencies overall. In this way, they were able to fulfill an objective of this paper by statistically clarifying that this course (utilizing peer evaluation in group work) is an effective program for developing the Fundamental Competencies for Working Persons, regardless of whether or not the CS Group Evaluation was implemented. Moreover, confirming the items with high growth values over the two-year period-(3) 
execution skill, (7) ability to deliver messages, and (8) ability to listen closely and carefully (three items) for classes with the CS Group Evaluation, and (7) ability to deliver messages and (8) ability to listen closely and carefully (two items) for classes without the CS Group Evaluation-suggested that (3) execution skill is particularly developed by implementing the CS Group Evaluation.

\section{Comparison and Verification of Growth Values for Classes that Did and Did Not Implement the CS Group Evaluation (Analysis 2)}

Verifying the effects of the CS Group Evaluation (an objective of this paper), numerical results were compared for the classes with the CS Group Evaluation and those without. These results are shown in Table 3.

Table 3. Comparison in growth-values between the control and non-control groups (FY2014/FY2015).

\begin{tabular}{|c|c|c|c|c|c|c|c|c|c|c|}
\hline \multirow[b]{3}{*}{$\begin{array}{l}\text { Fundam ental C om petenc ies } \\
\text { for W orking Persons }\end{array}$} & \multicolumn{5}{|c|}{ FY2014 } & \multicolumn{5}{|c|}{ FY2015 } \\
\hline & \multicolumn{3}{|c|}{ G row th-value } & \multirow{2}{*}{\multicolumn{2}{|c|}{$P$-value }} & \multicolumn{3}{|c|}{ G row th-value } & \multirow{2}{*}{\multicolumn{2}{|c|}{$P$-value }} \\
\hline & $\begin{array}{c}\text { C lass A N=50) } \\
\text { w ith Council } \\
\text { System G roup } \\
\text { Evaluation }\end{array}$ & $\begin{array}{c}\text { C lass B } \quad \mathrm{N}=55) \\
\text { w ithout C ounc il } \\
\text { System G roup } \\
\text { Evaluation }\end{array}$ & $\begin{array}{c}D \text { ifference } \\
(A-B)\end{array}$ & & & $\begin{array}{c}\text { C lass A } \quad \mathrm{N}=55) \\
\text { w ith Counc il } \\
\text { System G roup } \\
\text { Eva luation }\end{array}$ & $\begin{array}{c}\text { C lass B } \quad \mathrm{N}=55) \\
\text { w ithout Counc il } \\
\text { System G roup } \\
\text { Evaluation }\end{array}$ & $\left|\begin{array}{c}D \text { ifference } \\
(A-B)\end{array}\right|$ & & \\
\hline \multicolumn{11}{|l|}{ Action } \\
\hline (1) In itiative & 0.52 & 0.35 & 0.17 & 0.285 & & 0.84 & 0.62 & 0.22 & 0.589 & \\
\hline (2) Ability to infuence & 0.60 & 0.45 & 0.15 & 0.356 & & 0.98 & 0.60 & 0.38 & 0.024 & ** \\
\hline (3) Execution skill & 0.74 & 0.33 & 0.41 & 0.049 & ** & 1.16 & 0.66 & 0.50 & 0.003 & $* * *$ \\
\hline Subtota & 1.86 & 1.13 & 0.73 & 0.035 & ** & 2.89 & 1.87 & 1.02 & 0.003 & $* * *$ \\
\hline \multicolumn{11}{|l|}{ Thinking } \\
\hline (4) Ability to detect issues & 0.58 & 0.28 & 0.30 & 0.140 & & 0.84 & 0.39 & 0.45 & 0.008 & $* * *$ \\
\hline (5) P lann ing skill & 0.70 & 0.36 & 0.34 & 0.076 & * & 0.74 & 0.44 & 0.30 & 0.021 & ** \\
\hline (6) C reativity & 0.72 & 0.20 & 0.52 & 0.008 & $* * *$ & 0.62 & 0.42 & 0.20 & 0.210 & \\
\hline Subtota & 2.00 & 0.83 & 1.17 & 0.003 & $* * *$ & 2.20 & 1.24 & 0.96 & 0.013 & ** \\
\hline \multicolumn{11}{|l|}{ Team w ork } \\
\hline (7) Ability to de liver m esseges & 0.84 & 0.50 & 0.34 & 0.084 & * & 1.00 & 0.90 & 0.10 & 0.457 & \\
\hline $\begin{array}{l}\text { (8) Ability to listen c bsely } \\
\text { and carefully }\end{array}$ & 0.76 & 0.40 & 0.36 & 0.048 & ** & 1.07 & 0.84 & 0.23 & 0.256 & \\
\hline (9) Flexbility & 0.40 & 0.24 & 0.16 & 0.310 & & 0.49 & 0.43 & 0.06 & 0.526 & \\
\hline (10) Ability to grasp situation & 0.46 & 0.27 & 0.19 & 0.295 & & 0.60 & 0.42 & 0.18 & 0.167 & \\
\hline $\begin{array}{l}\text { (11) Ability to apply rules and } \\
\text { regulations }\end{array}$ & 0.56 & 0.28 & 0.28 & 0.102 & * & 0.60 & 0.28 & 0.32 & 0.068 & $*$ \\
\hline (12) Ability to contro I stress & 0.52 & 0.34 & 0.18 & 0.604 & & 0.96 & 0.56 & 0.40 & 0.034 & ** \\
\hline Subtota & 3.54 & 2.02 & 1.52 & 0.019 & ** & 4.72 & 3.43 & 1.29 & 0.069 & $*$ \\
\hline \multirow{2}{*}{\multicolumn{6}{|c|}{\begin{tabular}{r|r|r|r|r}
3.98 & 3.42 & 0.002 & $* * *$ \\
$* * *<0.01$ & $* *<0.05 *$ & $*<0.10$
\end{tabular}}} & 9.81 & 6.54 & 3.27 & 0.006 & $* * *$ \\
\hline & & & & & & \multicolumn{5}{|c|}{$* * *<0.01, * *<0.05, *<0.10$} \\
\hline
\end{tabular}

Modified from Fujihara and Maeno (2017) [17]

As shown in Table 3, the classes with the CS Group Evaluation had higher Fundamental Competencies for Working Persons growth values than the classes without in both FY2014 and FY2015. Furthermore, statistically judging the results of the CS Group Evaluation, the growth values from both the classes with and without the CS Group Evaluation were confirmed by conducting the Wilcoxon signed-rank test. In FY2014, the class with the CS Group Evaluation showed significant improvements overall for all three competencies. Regarding the 12 factors, even separately, significant differences at the $5 \%$ level were recognized for (3) execution skill, (6) creativity, and (8) ability to listen closely and carefully. In FY2015 as well, all three competencies were significantly improved overall for the class with CS Group Evaluation. Regarding the 12 factors, even separately, significant differences at the $5 \%$ level were recognized for (2) ability to influence, (3) execution skill, (4) ability to detect issues, (5) planning skill, (11) ability to apply rules and regulations, and (12) ability to control stress.

In this way, the authors statistically clarified that the CS Group Evaluation is effective for developing the Fundamental Competencies for Working Persons. Moreover, confirming which 
items had large significant differences over the two years showed that (3) execution skill was high. This suggests that (3) execution skill is particularly developed by implementing the CS Group Evaluation. However, some items in Table 3 show remarkable differences in statistical significance between FY2014 and FY 2015 while others do not. It is presumed that these differences can be attributed to the effectiveness of the group work. This must be further researched going forward.

\section{Comparison and Verification of Post-Class Evaluation Mean Values for Group Evaluation and Individual Evaluation (Analysis 3)}

Finally, the mean values in the post-class evaluation were compared between the group evaluation and individual evaluation to verify whether working as a group is more effective than individual work for developing the Fundamental Competencies for Working Persons (an objective of this paper). The results are shown in Table 4. This comparison was made based on the idea that the Fundamental Competencies for Working Persons would be higher for the group evaluation than individual evaluation, due to increasing group awareness when implementing the CS Group Evaluation in each class.

Table 4. Comparison of post-class evaluation average values between CS Group Evaluation and self-evaluation of Class A (FY2014/FY2015).

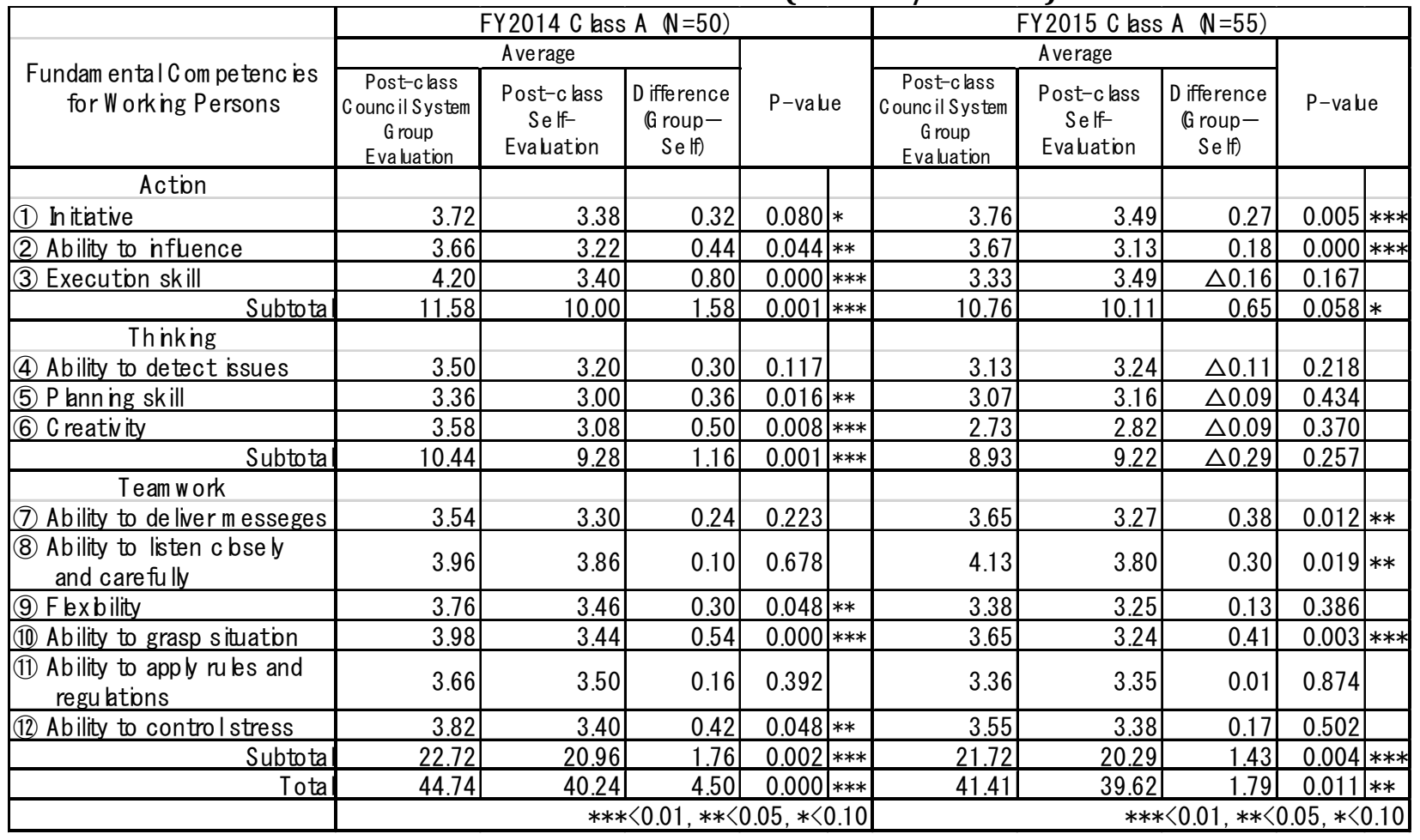

Modified from Fujihara and Maeno (2017) [17]

As shown in Table 4, the results of the group post-class evaluation were higher than those of the individual self-evaluation for all competency factors in FY2014. Moreover, when comparing these results with the Wilcoxon signed-rank test, the mean group evaluation values had significantly improved overall for the three competencies. Among the 12 factors, statistically significant differences at the $5 \%$ level were recognized for (2) ability to influence, (3) execution skill, (5) planning skill, (6) creativity, (9) flexibility, (10) ability to grasp situations, and (12) ability to control stress. Similarly, in FY2015, the mean group evaluation values had significantly improved overall for the three competencies. Among the 12 factors, statistically significant differences at the 5\% level were recognized for (1) initiative, (2) ability to influence, (7) ability to deliver messages, (8) ability to listen closely and carefully, and (10) ability to 
grasp situations. No statistically significant differences were recognized for individual evaluation, although there were some factors for which individual evaluations had higher mean values than group evaluations.

In this way, the authors statistically clarified that the group evaluation had higher Fundamental Competencies for Working Persons than the individual evaluation when the CS Group Evaluation was implemented. Furthermore, confirming items with high mean group evaluation values over the two years ([2] ability to influence and [10] ability to grasp situations) suggests the possibility that these factors are particularly developed by classes that incorporate group work. However, similar to Analysis 2, some items in Table 4 show remarkable differences in statistical significance between FY2014 and FY2015 while others do not. It is presumed that the differences can be attributed to the effectiveness of the group work. This must be further researched going forward.

\section{CONCLUSION}

The hypothesis of this research is that group awareness can be enhanced to increase the Fundamental Competencies for Working Persons by implementing the CS Group Evaluation, in addition to peer evaluation in business manner education. In this research, first, we showed the CS Group Evaluation, the characteristic point of this research, in the form of a matrix (Figure 2). Second, we proposed the new CS Group Evaluation method from the viewpoint of the Fundamental Competencies for Working Persons, for role-playing group work in Japanese business manner education. We then analyzed the results of a Fundamental Competencies for Working Persons self-evaluation questionnaire survey administered to 210 students, statistically clarified the educational effects of this program and evaluation method of the Fundamental Competencies for Working Persons development, and also engaged in deeper consideration of the educational effects. Specifically, we compared and analyzed the results from the pre- and post-class surveys, confirmed the results of peer evaluation in group work, compared and analyzed the classes with and without CS Group Evaluation, and confirmed the effects of that evaluation. Moreover, we compared and analyzed the CS Group Evaluation and individual evaluation, clarifying that the former evaluations were higher than the latter. Finally, we organized the effects and significance of the Fundamental Competencies for Working Persons development, utilizing CS Group Evaluation in group work.

Throughout this research, the authors sought to enumerate what elements of the effects of peer evaluation and CS Group Evaluation of the Fundamental Competencies for Working Persons are considered important in Japanese business manner education.

1) Utilizing peer evaluation in group work, comparisons between and verifications of the pre- and post-class evaluations (Analysis 1) showed that this course was an effective program for developing the Fundamental Competencies for Working Persons regardless of whether or not the classes implemented the CS Group Evaluation.

2) Comparisons between and verifications of the growth values for the classes with and without CS Group Evaluation (Analysis 2) showed that such evaluation is more effective for developing the Fundamental Competencies for Working Persons than individual evaluation. Moreover, this suggested that (3) execution skill is particularly developed by implementing the CS Group Evaluation.

3) Comparing and verifying the post-class evaluation mean values for the CS Group Evaluation and individual evaluation (Analysis 3) showed that, when the former is implemented, the Fundamental Competencies for Working Persons were higher than for the individual evaluation. Moreover, this suggested that the CS Group Evaluation develops the (2) ability to influence and (10) ability to grasp situations in particular. 
Therefore, this research was able to confirm that the use of the CS Group Evaluation in Japanese business manner education produced a certain level of effects from the perspective of the Fundamental Competencies for Working Persons.

This research has clarified the effects of the CS Group Evaluation and peer evaluation in group work using role-playing as a part of Japanese business manner education, from the viewpoint of the Fundamental Competencies for Working Persons. Although it comprised continuous research spanning two years, this research only targeted students at one private university and cannot therefore be generalized. Therefore, going forward, research and analyses must be conducted to ascertain if the results are supported in effect measurement in other courses and universities and if they are supported outside of Japan. It is also thought that factors such as whether or not the group work went well, impacted the Fundamental Competencies for Working Persons items that had higher effects in different fiscal years. Further research is necessary including interviews and observations of councils during the CS Group Evaluations during class time. In the future, aiming to contribute to the educational quality of Fundamental Competencies for Working Persons development programs at universities, the authors hope to systematize this educational program that utilizes the CS Group Evaluation in group work as well as its effect measurement.

\section{SUPPLEMENTARY NOTE}

This paper summarizes the results of and expands upon a study note [17] published in the Japanese Applied Business Studies Review in 2017.

\section{References}

Central Council for Education in Ministry of Education, Culture, Sports, Science and Technology. The way of career education: Vocational education in future schools.

http://www.mext.go.jp/b_menu/shingi/chukyo/chukyo10/sonota/1293955.htm. (accessed 2016-12-01)

Education reproduction meeting in Cabinet Office. Total cost of education reproduction in society, 2007. http://www.kantei.go.jp/jp/singi/kyouiku/houkoku/gaiyou0601.pdf (accessed 2016-12-01)

Ministry of Economy, Trade and industry, Fundamental competencies for working persons, 2006. http://www.meti.go.jp/policy/kisoryoku/kisoryoku_image.pdf. (accessed 2016-12-01)

Fujihara, Y. and Maeno, T., The effectiveness of the business manner education using peer review. Applied Business Studies Review, 2015. 33(3): p. 1-12.

Ikari, T., Class implementation report of career design in Nara Saho College. Bulletin of Studies, 2015. 23(4): p. 2532.

Tanimoto, H., The purpose of this study was to examine the effect of creative activity in dance classes, as a form of active learning, on interpersonal relationships and the generic skill of teamwork competency. Osaka Sangyo University Bulletin, 2016. 15(3): p. 21-33.

Central Council for Education in Ministry of Education, Culture, Sports, Science and Technology. A qualitative change in university education to build the new future.

http://www.mext.go.jp/component/b_menu/shingi/toushin/_icsFiles/afieldfile/2012/10/04/1325048_1.pdf. (accessed 2016-12-01)

The Encyclopedia of Contemporary Education Evaluation, 1998. Kaneko Shobo Publishing.

Kagawa, M., New evaluation methods of cooking practices in high school home economics: Group evaluation and individual evaluation. Faculty of Human Sciences, Matsuyama Shinonome College Bulletin, 2008. 16(3): p. 11-18.

Adachi, K., and S. Nakao. The relationship between group-based activity process, results and members' characteristics in CSCW. Japan Journal of Educational Technology, 2000. 24(4): p. 73-78.

Nishitani, S. Introduction of the team evaluation in active learning. Departmental Bulletin Paper of Kyoto University Research Information Repository, 2014. 1909(8): p. 223-232. 
Tamura, Y., et al. Perceptions on collaborative practice of pressure sore team member. Kobe University School of Medicine Bulletin, 2004. 20(4): p. 21-33.

Misawa, R., et al. Study on team evaluation (6) Relationships among technical skill proficiency, leadership, and teamwork behaviors. Central Research Institute of Electric Power Industry, 2011. 1-17(4): p. 1-3.

Kojien, $7^{\text {th }}$ edition, 2008. Iwanami Publishing.

Ministry of Economy, Trade and Industry, Upbringing and evaluation of fundamental competencies for working persons. Kadokawa Gakugei Publishing.

Ministry of Economy, Trade and industry, The encouragement of fundamental competencies for working persons. http://www.meti.go.jp/policy/kisoryoku/2006chosa.pdf. (accessed 2016-12-01)

Fujihara, Y., and Maeno, T. The effectiveness of business manner education using peer review and team review on "Fundamental Competencies for Working Persons". Applied Business Studies Review, 2017. 35(3): p. 57-58 (in Japanese). 